\title{
PROBLEMATIKA KEBUDAYAAN DALAM PENERJEMAHAN BAHASA ARAB KE BAHASA INDONESIA
}

\author{
Khoirul Huda \\ Institut Agama Islam Negeri (IAIN) Metro \\ Jl. Ki Hajar Dewantara 15A Iring Mulyo Kota Metro \\ irulhuda55@gmail.com
}

\begin{abstract}
Translation as an activity and translation as a result of activities can not be separated from the concept of culture. Translation has an important role in the development of culture, translating means comparing culture. The link between language and culture gives rise to the implication that translation is not only understood as a transfer of form and meaning, but also as a cultural diversion. Consequently, translation activities can not only experience language barriers, but also cultural constraints. In this regard the task of the translator is not just to look for lexical and grammatical equivalents, but also to find appropriate ways to express things in the target language.Looking at the background above, the writer will present briefly in his discussion of cultural problems in translating Arabic into Indonesian. The problem formulation of this discussion is: What are the cultural problems faced by translators of Arabic into Indonesian, and How to deal with cultural problems in translating Arabic into Indonesian.
\end{abstract}

Keywords: Translation, Culture, Arabic Lenguage.

\section{Abstrak}

Penerjemahan sebagai suatu kegiatan dan terjemahan sebagai hasi dari kegiatan tidak dapat dipisahkan dari konsep budaya. Terjemahan memiliki peranan penting dalam pengembangan budaya, menerjemahkan berarti membandingkan budaya.Keterkaitan bahasa dan budaya melahirkan implikasi bahwa penerjemahan tidak saja dipahami sebagi pengalihan bentuk dan makna, tetapi juga sebagai pengalihan budaya. Konsekuensinya, kegiatan penerjemahan tidak saja dapat mengalami kendalabahasa, tetapi juga kendala budaya.Dalam kaitan inilah tugas penerjemah sesungguhnya tidak sekadar mencari padanan leksikal dan gramatikal, tetapi juga menemukan cara yang sesuai untuk mengungkapkan sesuatu dalam bahasa target. Melihat latar belakang di atas, maka penulis akan memparkan dengan ringkas dalam pembahasannya tentang problematika budaya dalam penerjemahan bahasa Arab ke bahasa Indonesia.

Kata Kunci: Penerjemahan, Budaya, Bahasa Arab.

\section{Pendahuluan}

Di era globalisasi ini komunikasi

lintas bahasa dalam bentuk penerjemahan masih eksis, bahkan cenderung semakin penting. No global communication without translation tak ada komunikasi global tanpa penerjemahan, demikian ujar Newmark. Tak terkecuali kegiatan penerjemahan dari bahasa 
Arab ke dalam bahasa Indonesia juga semakin marak seiring dengan meningkatnya ghirah 'semangat' keberagaman umat Islam di Indonesia. Hal ini dibuktikan dengan banyaknya buku terjemahan, terutama yang berhubungan dengan khazanah Keislaman, seperti Al-Qur'an, hadis, tafsir, fikih, akhlak, akidah, tasawuf, dan lain-lain. ${ }^{1}$

Hal senada juga juga disampaikan oleh A. Warson Munawir dalam pengantar buku Pintar Menejemahkan Arab-Indonesia, bahwa perhatian masyarakat terhadap bahasa Arab dewasa ini semakin bertambah seiring meningkatnya kebutuhan akan penerjemahan teks-teks bahasa Arab ke Indonesia di kalangan terpelajar juga kalangan profesional dan lainnya. ${ }^{2}$

Menerjemahkan sering kali dianggap sebagai sesuatu yang mudah. Padahal orang yang mengerti bahasa sumber dan bahasa sasaran yang merupakan komponen utama dalam penerjemahanbelum tentu menjadi jaminan bahwa dia bisa menerjemahkan dengan baik dan andal. Hal inilah yang banyak tidak disadari sehingga tidak aneh bila ada orang yang memiliki sedikit penguasaan bahasa sumber sudah berani menjadi seorang

${ }^{1}$ Zaka Al Farisi, Pedoman Penerjemahan Arab Indonesia Strategi, Metode, Prosedur, dan Teknik, (Bandung: PT Remaja Rosda Karya, 2011) h. 1

${ }^{2}$ Nur Mufid dkk, Buku Pintar Menerjemah Arab-Indonesia (Cara Paling Tepat, Mudah dan Kreatif, (Surabaya: Pustaka Progressif, 2007), h. Pengantar. penerjemah.

Menerjemahkan merupakan keahlian yang butuh untuk terus diasah, dibimbing, dan dilatih. Itu saja belum cukup bila penerjemahan tidak memiliki wawasan yang cukup baik karena kegiatan penerjemahan merupakan kajian antarilmu (interdisipliner). Itu berarti menerjemahkan memerlukan ilmu pengetahuan lain yang bersifat pendukung, seperti semantik, pragmatik, sosiolinguistik, budaya, pengetahuan umum, dan sebaginya. Jadi, selain penerjemah harus memiliki wawasan yang luas, dia juga harus mengerti bagaimana cara mengungkapkannya dalam bahasa sasaran yang biasa dikenal dengan ta'bir'.

Salah satu masalah yang pelik dalam penerjemahan adalah terkait dengan persoalan budaya. Persoalan ini biasanya berhubungan dengan ungkapan-ungkapan kebudayaan semisal kinayah, isti'arah, tasybih, dan sebangsanya. Persoalan ini muncul manakala bahasa target tidak memiliki ungkapan yang sepadan dengan bahasa sumber, sehingga sulit ditemukan atau tidak ditemukan padanan yang paling mendekati dalam bahasa target. Berkaitan dengan ini tugas penerjemah ialah menemukan cara yang tepat untuk mengungkapkan istilahistilah budaya dalam bahasa target.

${ }^{3}$ Moch. Syarif Hidayatullah, Cakrawala Linguistik Arab, Jakarta: PT Grasindo, 2017, h. 161162 
Penerjemahan sebagai suatu kegiatan dan terjemahan sebagai hasi dari kegiatan tidak dapat dipisahkan dari konsep budaya. Terjemahan memiliki peranan penting dalam pengembangan budaya, menerjemahkan berarti membandingkan budaya ${ }^{4}$. Keterkaitan bahasa dan budaya melahirkan implikasi bahwa penerjemahan tidak saja dipahami sebagi pengalihan bentuk dan makna, tetapi juga sebagai pengalihan budaya. Konsekuensinya, kegiatan penerjemahan tidak saja dapat mengalami kendalabahasa, tetapi juga kendala budaya. Dalam kaitan inilah tugas penerjemah sesungguhnya tidak sekadar mencari padanan leksikal dan gramatikal, tetapi juga menemukan cara yang sesuai untuk mengungkapkan sesuatu dalam bahasa target. Menurut Thriveni makna berkonteks budaya terajut sangat ruwet (intricately woven) dalam tekstur bahasa, sehingga penerjemah dituntut memiliki kejelian dalam menyikapi dua budaya yang berbeda. Penerjemah harus bisa menangkap warna budaya yang terdapat dalam bahasa sumber seraya mengungkapkannya dalam terjemahan yang dapat dipahami oleh pembaca bahasa target ${ }^{5}$.

${ }^{4}$ Roswita Silalahi, Penerjemahan dan Penyebaran Nilai-Nilai Budaya: Dalam Konteks Sejarah, Pusat Bahasa dan Seni Unimed: Jurnal Bahas No 59 Okt-Des 2005. h. 4

${ }^{5}$ Zaka Al Farisi, Ibid. h. 94
Berdasarkan dengan judul penelitian oleh penulisn Syahabuddin Nur mengenai "Problematika Linguistik dalam penerjemahan Arab ke Indonesia "maka diperlukan pembahasan lebih lanjut tentang aspek budaya yang menjadi sisi lain dari sebuah bahasa, dan hal ini sangatlah terkait tentang bagaimana seorang penerjemah itu harus mencari padanan kata yang bersifat kultural.

Melihat latar belakang di atas, maka penulis akan memparkan dengan ringkas dalam pembahasannya tentang problematika budaya dalam penerjemahan bahasa Arab ke bahasa Indonesia. Adapun Rumusan masalah dari pembahasan ini adalah sebagi berikut:

1) Apa saja problematika kebudayaan yang dihadapi oleh penerjemah bahasa Arab ke bahasa Indonesia?

2) Bagaimana upaya untuk mengatasi problematika kebudayaan dalam penerjemahan bahasa Arab ke bahasa Indonesia?

Berdasarkan rumusan masalah di atas, maka dapat dirumuskan tujuan dalam penelitian ini, antara lain:

1) Untuk mengetahui problematika kebudayaan yang dihadapi oleh penerjemah bahasa Arab ke bahasa Indonesia.

2) Untuk mengetahuiupaya untuk mengatasi problematika kebudayaan dalam penerjemahan bahasa Arab ke bahasa Indonesia. 


\section{Pembahasan}

\section{a) Definisi budaya}

Dalam The World Book Encyclopedia didefinisikan bahwa budaya adalah “.... A term used by social scientist for a way of life. Every human society has a culture.Culture includes society arts, beliefs, customs, institutions, inventions, language, technology and values". Menurut Newmark budaya adalah “... a way of life and itsmanifestations that are peculiar to a community that uses a particular language as its means ofexpression". Nidadalam Eva Hung mendeskripsikan bahwa budaya berhubungan dengan totalitas kepercayaan da kebiasaan-kebiasaan yang berkaitan dengan masyarakat.

Menurut E.D Hirsch, penulis dari Amerika, yang menulis Dictionary of Cultural Literacy dan menjadi best seller disana, mengungkapkan bahwa budaya adalah:

“...this common knowledge allows people to communicate, to work together, and tolive together. It forms the basis for communities, and if it is shared by enough people,it is a distinguishing characteristic of a national culture. The form and content of this common knowledge constitute one of the elements that makes each national culture unique ... This... body of knowledge... identifies the names, phrases, events and otheritems that are familiar to most (people of a nation)".
Menurut Jin dan Nida dalam Eva Hung mengatakan bahwa:

"Language competence, in the sense of being bilingual, is not enough, unless it is also matched by a person's being bicultural. That is to say, one must have an intimate knowledge of the culture in question. One must be able to recognize subtle ironies and literary allusions. Dictionaries and encyclopedias can be very helpful in dealing with lexical problems, but they rarely go far enough in providing the kind of information which is necessary to understand cultural differences. Unless, for example, one understands that in one language-culture humour is based on understatement, while inanother it is usually a matter of overstatement, a translator is very likely to miss the points".

Dari keterangan di atas baik Nida maupun Hirsch mengakui bahwa pengetahuan budaya adalah kumpulan pengetahuan yang mendasari pengetahuan yang lain, terutama dalam bidang penerjemahan. Dari batasan mengenai budaya di atas dapat disimpulkan bahwa budaya adalah cara hidup suatu bangsa dan bahasa termasuk dalam system budaya ${ }^{6}$.

\section{b) Bahasa dan Budaya}

Menurut Koentjaraningrat bahwa bahasa bagian dari kebudayaan. Jadi, hubungan antara bahasa dan kebudayaan merupakan hubungan yang subordinatif, dimana bahasa berada di bawah lingkup kebudayaan. Namun,ini bukanlah satu-satunya konsep yang

\footnotetext{
${ }^{6}$ Nuning Yudhi Prasetyani, Penerjemahan dan Budaya, Jombang: Jurnal Diglossia UNIPDU, 2009. h. 7-9
} 
ada dibicarakan orang, sebab di samping itu ada pendapat lain yang menyatakan bahwa bahasa dan kebudayaan mempunyai hubungan yang koordinatif, yakni hubungan yang sederajat, yang kedudukannya sama tinggi. Kalau kebudayaan itu adalah satu sistem yang mengatur interaksi manusia didalam masyarakat, maka kebahasaan adalah suatu sistem yang berfungsi sebagai sarana berlangsungnya interaksi itu ${ }^{7}$.

Ibarat dua sisi dari sebuah koin, bahasa dan budaya saling terkait. Hubungan antara bahasa dan budaya tidak bisa dipisahkan satu sama lain. Pemertahanan atau pergeseran bahasa bisa dipastikan bisa berimbas pada budayanya. Begitupun sebaliknya. Nilai-nilai budaya yang dianut oleh sebuah kelompok tercermin dalam perilaku kebahasaan mereka. Dalam kaitan ini, meminjam istilah Bassnett, bahasa merupakan the heart within the body of culture jantungnya budaya. Ini berarti denyut budaya suatu masyarakat sangat dipengaruhi oleh bahasanya. Lebih tedas Bloomfield menyatakan bahwa sedemikian kuat hubungan bahasa dan budaya sampai-sampai kekayaan atau kemiskinan suatu budaya tercermin dalam bahasanya. Cerminan budaya dalam bahasa tidak terbatas pada tataran kosakata saja, tetapi juga terdapat pada

\footnotetext{
${ }^{7}$ Abdul Chaer, Sosiolinguistik Perkenalan Awal, Jakarta: Rineka Cipta, 2010, h. 165
}

tataran yang lebih luas seperti pada aspek retorika.

Bahasa adalah tingkah laku manusia yang berpola, demikian papar Catford. Sebagai subsistem budaya, bahasa mempunyai seperangkat kaidah dalam pemakaiannya. Dalam praktiknya, setiap orang berbicara memakai bahasanya dan bereaksi sesuai dengan pola budayanya sendiri. Pandangan senada juga disampaikan Nida. Penerima pesan hanya dapat bereaksi terhadap pesan tersebut dalam bahasanya sendiri, dan hanya dapat mengungkapkan suatau respons sesuai dengan konteks budaya yang dimilikinya. Disini peran penerjemah bukan sekadar menumpangkan struktur budaya sumber pada struktur budaya target atau sebaliknya, tetapi juga mesti menyusun kembali (restructuring) dan menyelaraskan dalam kerangka buday target.

Pada kenyataannya, bahasa yang digunakan oleh penulis teks sumber sering kali memiliki kekhasan budaya yang berbeda dengan budaya yang dimiliki oleh penerjemah. Hal ini menimbulkan kesulitan tersendiri dalam menemukan dan menghadirkan padanan leksikal yang pas. Walhasil, masalah utama yang muncul dalam proses penerjemahan tidak hanya terkait dengan kesenjangan bahasa, tetapi juga terkait dengankesenjangan aspek budaya. Penerjemah sering kali menghadapi masalah bagaimana mengatasi aspek-aspek budaya yang secara implisit terdapat dalam sebuah 
teks sumber seraya menemukan teknik paling sesuai yang mampu mengungkapkan aspek-aspek budaya tersebut dalam bahasa target, demikian Nida mengungkapkan.

Bahasa sejatinya dipandang sebagai bagian dari suatu buadaya yang erat kaitannya dengan modus berpikir suatu masyarakat. Cara pandang dunia masyarakat Indonesia, misalnya, bisa dipastikan berbeda dengan cara pandang dunia masyarakat Arab. Ada matra budaya yang tercerminkan dalam bahasa. Mempelajari suatu bahasa berarti mempelajari budanyanya. Bahasa mesti dipelajari dalam konteks budaya, dan budaya bisa dipelajari melalui bahasa. Perbedaan budaya menghasilkan kosakata yang berbeda. Ini bisa dimaklumi mengingat stiap budaya mempunyai konsep-konsep khas dan unik yang berbeda satu sama lain. Walhasil, bahasa hanya mempunyai makna bila dibingkai dalam latar budayanya.

Pada taraf tertentu cara kita melihat dunia bergantung pada bahasa yang kita gunakan. Kita mengatagorikan objekobjek pengalaman kita dengan bantuan bahasa. Boleh jadi inilah yang menjadi sebab mempelajari dunia dan mempelajari bahasa merupakan aktivitas yang tidak dapat dipisahkan. Dunia kita sebagian ditentukan oleh bahasa kita. Bahasa menjadi prasyarat budaya. Pemikiranpemikiran yang canggih, menurut Hunt, bergantung pada manipulasi simbol-simbol. Boleh jadi simbol-simbol nonlinguistik semisal matematika, kimia, musik dan semacmnya, sudah canggih, tetapi simbolsimbol tersebut sangat terbatas. Sebaliknya, bahasa merupakan sistem simbol yang tidak terbatas. Ketakterbatasan simbol-simbol bahasa inilah yang memungkinkan manusia sanggup mengikat dan menguirai berbagai macamgagasan dan pemikiran.

Alhasil, bahasa mempengaruhi budaya. Dengan kata lain, bahasa mempengaruhi cara berpikir dan cara berperilaku masyarakat penuturnya. Jadi menurut principle of linguistic relativity ini, bahasalah yang membuat kita melihat realitas dengan cara tertentu. Konon masyarakat penutur bahasa yang mempunyai kategori kala sangat menghargai waktu. Jika masyarakat Amerika mengungkapkan, a clock runs 'jam berlari; masyarakat Indonesia mengatakan, waktu berjalan. Dari ungkapan ini tercermin bahwa masyarakat penutur bahasa yang tidak mempunyai kategori kala, semisal masyarakat Indonesia, kurang menghargai waktu. Istilah jam karet, molor juga mencandrakan betapa masyarakat penutur bahasa Indonesia sering menyia-nyiakan waktu. Bagaimana dengan masyarakat Arab yang menyatakan waktu bagaikan pedang; jika tak kau tebas, ia yang akan menebas kau'.

Dalam penerjemahan, perbedaan budaya dapat menimbulkan keterbatasan 
budaya. Yang dimaksud dengan keterbatasan budaya adalah ketidakmampuan mencari ataumendapatkan kata padanan ke dalam bahasa sasaran yang dikarenakan oleh adanya hambatanbudaya. Perbedaan budaya dapat menimbulkan keterbatasan perangkat leksikal bahasasasaran. Keterbatasan perangkat leksikal juga menjadi penghalang untuk memperoleh padanan yang tepat. Kata 'perforateur' yang mengacu pada alat perkantoran yang berfungsiuntuk melubangi kertas, sama sekali tidak mempunyai padanan dalam bahasa Indonesiadikarenakan tidak adanya perangkat leksikal yang dapat dijadikan padanan. Tidak adanyapadanan ini karena tidak tersediannya perangkat leksikal di dalam bahasa sasaran Keterbatasan perangkat leksikal ini sering berkaitan dengan produk-produk teknologi yang dihasilkan oleh Negara bahasa sumber.

\section{c) Problematika kebudayaan dalam penerjemahan bahasa Arab ke bahasa Indonesia}

Moch. Syarif Hidaytullah membagi problematika penerjemahan bahasa Arab ke bahasa Indonesia menjadi 12 kategori yang harus diperhatikan saat hendak menerjemahkan. Adapun kategori tersebut adalah $^{8}$ :

1) Perangkat Mental

Perangkat mental 9 Mental set) berhubungan dengan unsur-unsur yang

\footnotetext{
${ }^{8}$ Moch. Syarif Hidayatullah, Ibid, h. 59-67.
}

kita pikirkan saat dihadapkan pada suatu hal. Dalam hal ini, apa yang kita pikirkan terkait dengan kata tertentu, maka itu juga yang dimaksud dengan perangkat mental. Sebagai contoh, kata dalam bahasa Arab. Kata tersebut sering dipadankan dengan kata hari dalam bahasa Indonesia, padahal sebenarnya makna kata tersebut kadang tidak sama persis. Frasa يوم أحد misalnya, tidak bisa diterjemahkan dengan hari Ahad. Hal ini karena frasa tersebut pada konteks tertentu bermakna "waktu perang" bahkan sering kali hanya diterjemahkan dengan perang Uhud.

Isu perangkat mental pada kata hari bila memperhatikan struktur budaya Indonesia, hari dimjulai setelah di tengah malam, sedangkan hari dalam bahasa Arab dimulai setelah tenggelamnya matahari. Dalam struktur budaya Indonesia, kata hari juga digunakan untuk mengacu pada peristiwa bersejarah, penting, dan yang perlu diingat oleh khlayak, misalnya Hari Pahlawan, hari Guru, atau Hari Santri.

\section{2) Ungkapan Stereotip}

Ungkapan Stereotip ialah kalimat atau ujaran yang diucapkan hanya dalam situasi tertentu yang khusus. Ini seperti كبحان الله، ما yang penggunaannya terkadang tidak dapat dipertukarkan. Padanan untuk ungkapan-ungkapan semacam ini tampakknya mudah dan sederhana, padahal sering terjadi perbedaan konsep.

Dalam kasus سبحان الله، misalnya, ungkapan ini biasanya dipadankan dengan 
Mahasuci Allah, Namun, konsep Mahasuci Allah dalam bahasa Arab tidak selalu sama dengan konsep Mahasuci Allah dalam bahasa Indonesia. Ihwal semacam ini kadang-kadang menimbulkan kesulitan tersendiri bagi penerjemah, apalagi bila penerjemah tidak memahami situasi apa yang membuat ungkapan itu dikatakan atau dituliskan.

\section{3) Peristiwa Budaya}

Setiap negera mempunyai apa yang disebut dengan "Peristiwa Budaya". Peristiwa budaya berarti semua kejadian, hal, perkara, dan sebagainya, yang berhubunga dengan pikiran atau akal budi manusia. Di Arab Saudi, peristiwa tahunan ibadah Haji merupakan peristiwa budaya, selain terkait dengan ritual keagamaan umat Islam. Di Iran, peristiwa budaya juga bisa ditemui pada peringatan Karbala, setiap tanggal 10 Muharrom.

Sebagai contoh dalam konteks ibadah haji atau umroh, sering kaloi jamaah haji atau umroh di jalan-jalan atau lokasi sekitar Masjidil Haram menenmukan banyak orang yang meneriakka, Kalau si penerjemah hanya melihat arti kata itu di kamus, tentu tak akan banyak informasi yang bisa digambarkan. Mengapa? Karena di balik kata itu ada peristiwa buday, yakni tradisi saling berbagi dan bersedekah disekitar Tanah Haram itu begitu tinggi. Oleh karenanya, terjemahan yang tepat bukan "halal ... halal ...! tapi, 'silahkan diambil'.

\section{4) Bangunan Tradisional}

Sekarang ini banyak negara memiliki bangunan yang sama dengan yang terdapat di negara lain. Fenomena semacam ini barangkali karena adanya film-film di TV. Namun demikian, di masing-masing negara tersebut masih banyak juga bangunan yang mempunyai ciri khas lokal dan tidak terdapat di negara atau di daerah lain.

Di Mesir dapat ditemui الأهرام dan di Arab Saudi dapat ditemui كعبة Bangunan semacam ini dalam penerjemahannya menimbulkan banyak kesulitan bila si penerjemah tidak berhasil menghadirkan gambar atau deskripsi yang tepat mengenai bangunan tersebut. Dengan bantuan gambar atau video yang da di Internet tentang bangunan tradisional, seorang penerjemah akan terbantu dalam mendeskripsikannya.

\section{5) Kekerabatan}

Hal kekerabatan juga terdapat dalam suatunegara. Sistem kekerabatan ini tampaknya sederhana bagi yang memilikinya. Namun yang tampaknya sederhana bagi yang memilikinya. Namun, yang tampaknya sederhana itu ternyata menimbulkan banyak kesulitan bagi seorang penerjemah karena sistem kekerabatan ini berbeda dari bangsa atau etnik yang satu dengan yang lain.

Karena bahasa Arab mengenal pembeda gender dalam kata dan jalur ayah atau 
ibu, yang unik, dalam sistem kekerabatan خال- dan عم-عمّة dikenal istilah digunakan untuk عم-عمّة Penyebutan paman-bibi yang dari jalur bapak, sedangkan خال-خالة digunakan untuk paman-bibi yang jalur ibu. Hal ini jelas akan menimbulkan sedikit banyak kesulitan bagi seorang penerjemah.

\section{6) Bahasa Kolokial}

Seperti bahasa yang lain, bahasa Arab juga mengenal bahasa standar dan bahasa nonstandar. Fushha merupakan bahasa standar, sedangkan amiyah merupakan bahasa nonstandar. Untuk kasus fushha, seorang penerjemah biasanya tidak terlalu mengalami kesulitan karena sistem tata bahasa dan kosakatnya telah terstruktur dan banyak kamus yang dapat membantu.

Hal yang sama tidak terjadi pada bahasa amiyah. Penerjemah yang tidak terlalu mengenalai sistem budaya dan bahasa Arab, tentu akan kesulitan mengalihbahasakannya. Meskipun ragam amiyyah ini lebih sering ditemui dalam kegiatan informal dan tuturan, tidak jarang juga ragam ini bisa ditemui pada kegiatan formal dan tulisan. Di sinilah seorang penerjemah perlu memiliki wawasan ihwal bahasa amiyyah, baik dari buku, tayangan stasiun televisi negara-negara Arab, maupun komik, lagu, film, dan kartun Arab.

\section{7) Ekologi}

Ekologi terkait dengan flora, fauna, angin, dataran, dan bukit. Salah satu contoh yang bisa dihadirkan diantaranya soal sebutan untuk unta. Dalam bahasa Indonesia, hanya dikenal unta, tanpa ada sebutan lainnya yang menandakan ciri pembeda antara satu unta dengan unta lainnya. Berbeda dengan dalam bahasa Arab, unta dikenalkan dengan banyak nama sesuai umurnya. Ini terkait dengan unta yang merupakan bagian dari kebudayaan Arab. Berikut beberapa sebutan unta betina berdasarkan umurnya:

Bintu makhad: unta betina yang telah genap berusia setahun; Bintu Labun: unta betina yang sudah genap; Hiqqah: unta betina yang telah genap berusia tiga tahun; Jadza'ah: unta betina yang telah genap berusia empat tahun.

Di sinilah seorang penerjemah memerlukan wawasan kebudayaan terkait dengan aspek ekologi secara detail, agar dia tidak salah dalam mencarikan padanan.

\section{8) Budaya Material}

Budaya Material berarti hasil karya dan karsa manusia berupa benda yang meliputi hal-hal sebagai berikut.
a) Makanan, seperti ثريد.
b) Pakaian, seperti برقع، جلباب، خف عقال;.
c) Senjata, seperti منجنيق.

Dalam penerjemahan hal-hal yang termasuk dalam kategori budaya material, 
seorang penerjemah perlu memahami secara jelas bentuk, kegunaan, fungsi, dan ciri khusunya. Saatini, dengan bantuan internet dalam bentuk gambar atau video, seorang penerjemahakan dengan mudah mendapatkan gambaran terkait dengan benda-benda hasil kebudayaan seperti yang disebutkan di atas, atau benda-benda lain sejenisnya.

\section{9) Konsep Agama}

Konsep agama merupakan ide atau pengertian terkait dengan istilah-istilah khusus yang terkait dengan ajaran-ajaran pokok dalam agama yang meliputi aspek akidah, ibadah, dan muamalah. Karena agama Islam secara kebetulan diturunkan di kawasan Arab, konsep-konsep Islam جنب، تيمم، سعي، seperti terlihat pada kata dan yang lainnya, perlu mendapat perhatian dari penerjemah agar dapat menginformasikan secara penuh maksud dari istilah-istilah itu, terutama bila hasil terjemahannya diperuntukkan bagi mereka yang belum mempunyai wawasan terkait konsep Islam itu.

\section{0) Isyarat dan Kebiasaan}

Setiap kebudayaan mempunyai isyarat dan kebiasaan yang khas dan berbeda dengan kebudayaan yang lain. Bahkan tak jarang isyarat dan kebiasaan yang sama, tetapi maknanya berbeda. Dalam kasus bahasa Arab, hal inibisa kita temukan pada kasus ayat berikut.
Dan berapa banyaknya kaum sesudah Nuh Telah kami binasakan. dan cukuplah Tuhanmu Maha mengetahui lagi Maha melihat dosa hamba-hamba-Nya.(QS AlIsro'17).

"Tangan terbelenggu pada leher" adalah simbol kikir yang bersumber pada isyarat tangan yang dikenal di kalanagn bangsa Arab. Isyarat dan kebiasaan seperti ini dengan makna "kikir", ternyata tidak dikenal dalam budaya bahasa Indonesia.

\section{1) Metafora}

Metafora adalah pemakaian kata atau kelompok kata bukan dengan arti yang sebenarnya, melainkan sebagai lukisan yang berdasarkan persamaan atau perbandingan.

Di Indonesia, metafora waktu adalah pedang sebenarnya berasal dari metafora bahasa Arab الوقت كالسيف, tetapi sudah sangat dikenal di Indonesia. Di dalam budaya orang Arab, pedang merupakan simbol pertahanan dan perlindungan atau sesuatau yang sangat penting. Karenanya, orang arab akan memperjuangkan segala hal yang dianggap mulia dan istemewa dengan pedang. Ini tentu saja berbeda dengan struktur budaya bahasa Indonesia.

\section{d) Upaya mengatasi problematika kebu- dayaan dalam penerjemahan bahasa Arab ke bahasa Indonesia}

Telah dijelaskan di atas, bahwa dalam proses menerjemahkan memerlukan beberapa hal sebagai bekal untuk menghasilkan karya 
terjemahan yang bermutu dan layak baca, dan dalam proses ini seorang penerjemah juga harus mempunyai keterampilan yang melibatkan banyak bakat daripada upaya dan teori.

Setiap bahasa mempunyai sitem sendiri. Sistem setiap bahasa adalah polisistemik karena setiap bahasa mempunyai struktur sintaksis, sintagmatik, leksikal dan morfem yang berbeda dari sistem bahasa lainnya. Sebuah kata dalam bahasa sumber mungkin memiliki makna yang sama sekali asing dalam budaya bahasa sasaran. Konsep itu bisa berkaitan dengan agama, adat istiadat atau jenis makanan. Konsep-konsep yang seperti ini sering disebut konsep khusus buadaya seperti yang telah dijelaskan pada sub judul di atas.

Dalam mencari padanan bagi kata yang berhubungan langsung dengan konsep-konsep buadaya, Mildred L. Larson menyarankan bagi penerjemah untuk mencari cara terbaik dalam mengungkapkan konsep-konsep kebudayaan itu. Ada tiga alternatif dasar yang dapat dipilih penerjemah untuk mencari padanan dalam bahasa sasaran: kata generik dengan frasa deskriptif. Kata asing (kata pinjaman), dan penggati kebudayaan. $^{9}$
Senada dengan penjelasan di atas Moch, Syarif menambahkan teknik penerjemahan kultural seperti adaptasi, pemadanan berkonteks, dan pemadanan bercatatan. Hal ini penting agar hasil terjemahannya tidak terasa asing dan kaku saat dibaca. Teknik penerjemahan kultural ini merupakan jalan keluar bagi seorang penerjemah agar terbebasa dari jarak ruang bahasa yang selalu dihadapi oleh penerjemah, terutama yang pemula. Adapun teknik itua adalah: ${ }^{10}$

1) Adaptasi. Teknik ini menuntut penerjemah untuk mengupayakan padanan kultural antara dua situasi tertentu. Sebagai contoh, seperti penerjemahan kalimat penghormatan untuk pejabat حضرة رئيس دائرة pada surat seperti kalimat ....... kalimat ini cukup diterjemahkan menjadi Yth. Bapak / Ibu .....

2) Pemadanan Bercatatan. Teknik ini dilakukan bila segala prosedur penerjemahan tidak dapat menghasilkan padanan yang diharapkan. Catatan dapat diberikan baik secara catatan kaki maupun catatan akhir pada setiap akhir bab.

3) Pemadan Berkonteks. Penerjemah dituntut untuk memberi suatu informasi dalam مؤسسة konteks agar maknanya jelas. Kata dalam bahasa Arab sering diterjemahkan dengan yayasan, padahal kata tersebut dalam bahasa Arab tidak hanya

\footnotetext{
${ }^{10}$ Moch. Syarif Hidayatullah, Ibid. h. 68-70 
digunakan untuk lembaga-lembaga yang mengelola kegiatan sosial, tetapi bisa juga digunakan untuk perusahaan komersil.

Selain tiga teknik di atas adan strategi lain yang dapat dimanfaatkan oleh penerjemah. Pertama, penerjemahan dengan menggunakan kata yang lebih umum. Sebagai contoh, penerjemahan kata شريد hanya diterjemahkan dengan 'bubur" saja, padahal bubu ini tidak sama dengan bubur yang dikenal pada umumnya di dalam kebudayaan kita. Kedua, penerjemahan menggunakan kata yang lebih netral. Sebagai contoh, frasa التقاء dalam kitab-kitab fikih, cukiup diterjemahkan dengan hubungan suamiistri.

Ketiga, penerjemahan dengan menggunakan pengganti kebudayaan. Sebagai contoh, peribahasa سبق السيف العذل yang diterjemahkan menjadi nasi sudah menjadi bubur. Atau, pepatah سلامة الإنسان في حفظ اللسان yang diterjemahkan menjadi mulutmu harimaumu. Keempat, penerjemahan dengan menggunakan kata serapan atau kata serapan yang disertai dengan penjelasan. Strategi ini sering digunakan dalam menerjemahkan kata yang berhubungan dengan kebudayaan, konsep modern, dan kata yang tidak jelas maknanya. Contohnya penerjemahan kata ke dalam bahasa Indonesia juga perlu penjelasan terkait dengan kebudayaan Arab yang terkandung dalam kata itu.

\section{Kesimpulan}

Berdasarkan uraian di atas dapat disimpulkan bahawa. Hubungan antara bahasa dan budaya tidak bisa dipisahkan satu sama lain. Pemertahanan atau pergeseran bahasa bisa dipastikan bisa berimbas pada budayanya. Begitupun sebaliknya. Nilai-nilai budaya yang dianut oleh sebuah kelompok tercermin dalam perilaku kebahasaan mereka. Dalam kaitan ini, meminjam istilah Bassnett, bahasa merupakan the heart within the body of culture jantungnya budaya.

Moch. Syarif Hidaytullah membagi problematika penerjemahan bahasa Arab ke bahasa Indonesia menjadi 12 kategori yang harus diperhatikan saat hendak menerDalam mencari padanan bagi kata yang berhubungan langsung dengan konsep-konsep buadaya, Mildred L. Larson menyarankan bagi penerjemah untuk mencari cara terbaik dalam mengungkapkan konsep-konsep kebudayaan itu. Ada tiga alternatif dasar yang dapat dipilih penerjemah untuk mencari padanan dalam bahasa sasaran: kata generik dengan frasa deskriptif. Kata asing (kata pinjaman), dan penggati kebudayaan jemahkan. Adapun kategori tersebut adalah: Pertama, perangkat mental, ungkapan stereotip, peristiwa budaya, bangunan tradisional, kekerabatan, bahasa kolokial, idiom, ekologi, budaya material, konsep agama, isyarat kebiasaan, dan metafora. 


\section{Daftar Pustaka}

Al Farisi, Zaka, Pedoman Penerjemahan Arab Indonesia Strategi, Metode, Prosedur, dan Teknik, Bandung: PT Remaja Rosda Karya, 2011

Chaer, Abdul, Sosiolinguistik Perkenalan Awal, Jakarta: Rineka Cipta, 2010

Mufid, Nur, dkk, Buku Pintar Menerjemah Arab-Indonesia (Cara Paling Tepat, Mudah dan Kreatif) Surabaya: Pustaka Progressif, 2007.

Syarif Hidayatullah, Moch, Jembatan Kata Seluk Beluk Penerjemahan Arab-Indonesia, Jakarta: PT Grasindo, 2017.

Yudhi Prasetyani, Nuning, Penerjemahan dan Budaya, Jombang: Jurnal Diglossia UNIPDU, 2009

Silalahi, Roswita, Penerjemahan dan Penyebaran Nilai-Nilai Budaya: Dalam Konteks Sejarah, Pusat Bahasa dan Seni Unimed: Jurnal Bahas No 59 Okt-Des 2005 
150 | II-Fathin Vol. 1 Edisi Juli-Desember 2018 